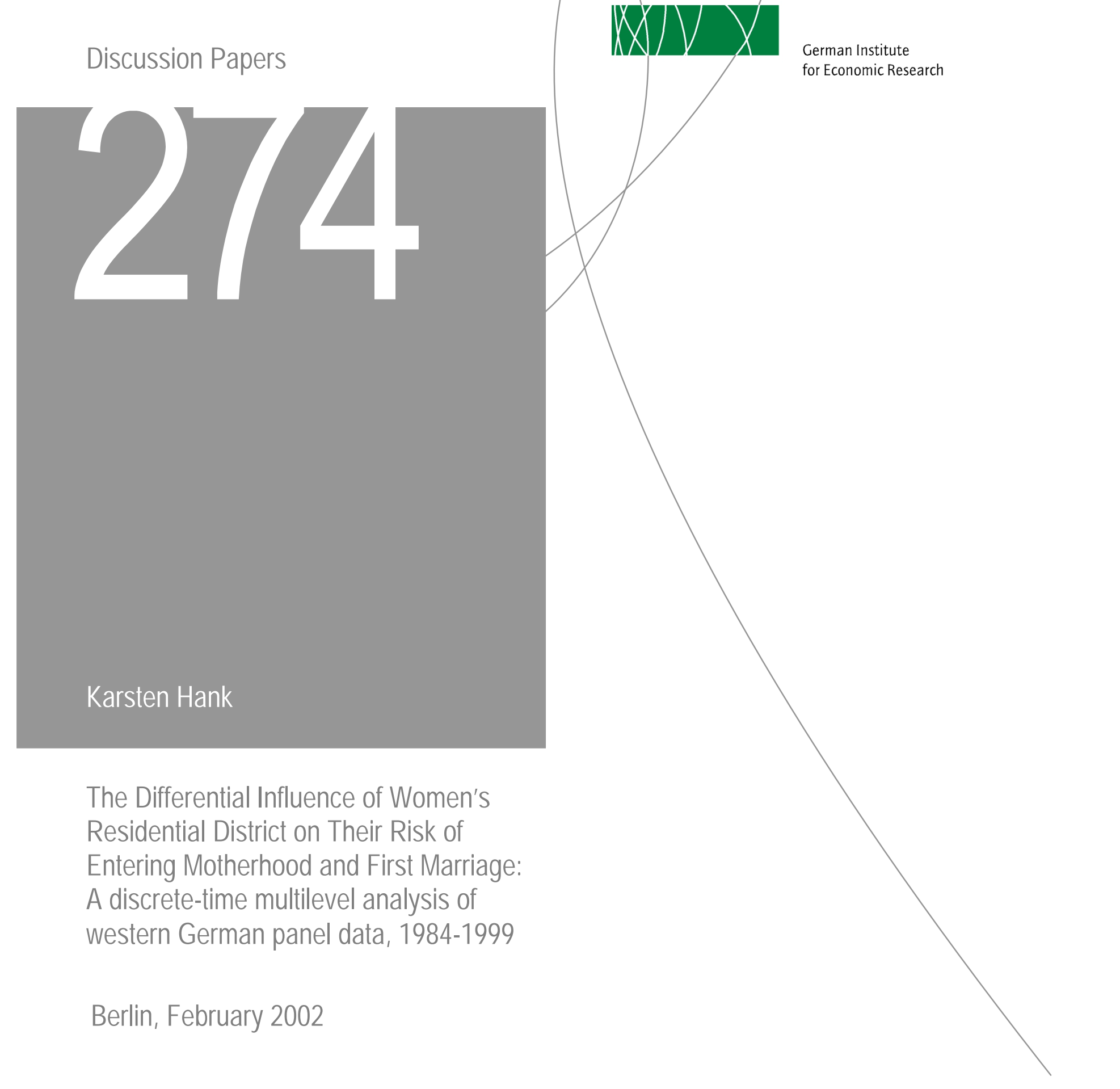


Opinions expressed in this paper are those of the author and do not necessarily reflect views of the Institute.

\section{DIW Berlin}

German Institute

for Economic Research

Königin-Luise-Str. 5

14195 Berlin,

Germany

Phone $+49-30-89789-0$

Fax +49-30-897 89-200

www.diw.de

ISSN 1619-4535 


\title{
The Differential Influence of Women's Residential District on Their Risk of Entering Motherhood and First Marriage A discrete-time multilevel analysis of western German panel data, 1984-1999
}

\author{
Karsten Hank ${ }^{\star}$
}

January 2002

\begin{abstract}
To begin with, we sketch a general multilevel model of regional social contexts and individual family formation behavior, where particular attention is paid to the determinants of the actor's situation. Then a set of bridge hypotheses is proposed, on which the empirical investigation of the relationship between properties of the spatial context and women's entry into motherhood and first marriage is based. Individual-level data from the German Socio-Economic Panel Study (GSOEP) are merged with a rich set of district-level contextual data to estimate first birth and marriage probabilities of western German women during the 1980s and 1990s. None of the estimated multilevel discrete-time logit models provides conclusive evidence for an autonomous contextual influence on women's entry into parenthood. We find, however, a persistent regional effect on the risk of entering first marriage, which we attribute to local nuptiality customs. Variations therein, e.g. regarding the timing of marriage, must probably be understood as the principal origin of different patterns of fertility across western German districts.
\end{abstract}

* Author's correspondence address: Max Planck Institute for Demographic Research, Doberaner Str. 114, 18057 Rostock, Germany. Telephone: +49-381-2081-163. Fax: +49-3812081-463. Email: hank@demogr.mpg.de.

The empirical analysis in this paper has been carried out during a research visit at the DIW Berlin in July 2001. Kind support of the GSOEP-Team, particularly Katharina Spieß, is gratefully acknowledged. I am indebted to Johannes Huinink and Hans-Peter Kohler for many helpful comments and suggestions. I would also like to thank Francesco Billari, Marcel Erlinghagen, and Jan Hoem for sharing with me their views on earlier drafts of this paper.

The views expressed in this paper are the author's views and do not necessarily reflect those of the Max Planck Institute for Demographic Research. 


\section{Introduction}

There is a large literature in the US dealing with the influence of neighborhood attributes - particularly community socio-economic status - on children's life chances (see Burton and Jarrett [2000]; Ginther, Haveman, and Wolfe [2000]; Jencks and Mayer [1990] for critical reviews of this literature). Moreover, neighborhood effects on a variety of family-related events have received increasing attention in recent years (e.g., Billy, Brewster, and Grady 1994; Billy and Moore 1992; South 2001; South and Crowder 2000). To our knowledge, there is barely any comparable research for the European setting. Recent studies using Scandinavian municipality data have investigated effects of the local day-care provision (Kravdal 1996) and regional employment levels (Hoem 2000) on individual fertility. Only lately, two studies were conducted that began to investigate whether regional fertility differentials in Germany persist, once individual characteristics are controlled for in the analysis. While Kopp (2000) uses data on seven selected Kreise (i.e. districts) from a regionalized survey, Hank (2001b) links individual-level data from the German Socio-Economic Panel with information on western German Raumordnungsregionen, which divide the country into 75 spatial units defined for the analysis of regional disparities and developments. These studies suggest that much of the variation in reproductive behavior between German regions is due to differences in the respective population composition. The present paper continues this research and extends it theoretically as well as empirically.

Although knowledge of the concrete mechanisms through which regional social contexts influence women's family formation behavior (e.g. opportunity structures, social interactions, cultural milieus) is crucially important, it is not sufficient for a full 
theoretical understanding of the interdependent relationship between social structure and individual action. However, while most contextual analyses implicitly refer to actor-based multilevel models, they are very rarely explicitly embedded in a general model of sociological explanation. This is done here, drawing heavily upon the work of Coleman (1990) and Esser (1996), and on the multilevel-system approach proposed by Huinink (1989).

In the empirical part of this paper, the process of family formation in western Germany during the 1980s and 1990s is placed into a regional context. A recent analysis of union formation dynamics and entry into parenthood in the 'old' Federal Republic shows that a high prevalence of non-marital cohabitation has lead to an overall delay of marriage, resulting in postponement of the first child (cf. Billari and Kohler forthcoming). After marriage, though, very high rates of transition into parenthood are observed, especially in the first year. Hence, a joint consideration of both events within a single analytical framework is highly desirable (see also Blossfeld and Huinink [1991]). In this study, multilevel discrete-time logit models are employed to estimate for the first time - contextual influences on western German women's probabilities to enter motherhood and first marriage, using the German Socio-Economic Panel (GSOEP) as an individual-level data source. To operationalize the social context, we use Kreise, which represent a clearly more local level of context than, for example, Raumordnungsregionen. In many respects Kreise should be more closely related to people's everyday life, and might also better correspond to frequently small-scale spatial patterns of fertility and nuptiality (cf. Bauereiß et al. 1997; Hank 2001a). In contrast to Kopp (2000), who merely distinguishes among rural and urban districts in an 
extremely small sample of Kreise, we have detailed information on all 328 western German Kreise at our disposal.

\section{Theoretical framework}

\subsection{A multilevel perspective on the explanation of social phenomena}

The study of the relationship between the individual and her social context continues to be one of the most important and most discussed issues in the social sciences until today (e.g., Alexander et al. 1987). However, by the middle of the twentieth century empirical social research had become increasingly 'atomistic', giving rise to an individualistic behaviorism that lacked connection with social theory and detached the actor from her social environment. Recent developments in multilevel modeling are therefore considered as an important contribution to the reconciliation between the micro and macro perspectives on social reality (e.g., DiPrete and Forristal 1994; Huber 1991).

It is crucial to recognize the micro-foundation of the multilevel approach: while the individual's scope of action is on the one hand determined by a set of given economic, social, and cultural opportunities and constraints ${ }^{1}$, a context's properties are simultaneously influenced by the behavior of its individual members. Thus, social development is characterized by the dialectic relationship between individual action and social structure (e.g., Erbring and Young 1979; Hernes 1976), where both are often conceptualized as dynamic, open, non-linear, i.e. self-referential and self-organizing

\footnotetext{
${ }^{1}$ The potential relevance of the natural environment is not denied, but will not be discussed here.
} 
social entities at separate levels of a hierarchical social system (cf. Huinink 1989: Chapter 2.3).

While the 'analytical primacy' of the social sciences is on the macro-level of analysis, its 'theoretical primacy' should be on the micro-level (e.g., Lindenberg 1990: 736). Stated differently, macro-social phenomena are the primary concern of social science, but the explanatory focus of the discipline is supposed to be on individual action and interactions between people. It has been argued that taking such an actorbased research perspective implies that any proposition attempting at an explanation of social phenomena must combine basically three successive analytic steps (e.g., Coleman 1990: 8; Esser 1996: 94ff.): First, the determinants of the situation in which the individual acts need to be identified, i.e. it takes a definition of the 'logic of the situation'. So called 'bridge hypotheses' (Esser 1998) relate the objective opportunities and constraints of a specific social situation to the individual's idiosyncratic expectations and her subjective interpretation and evaluation of the situation. Secondly, a theory of action is in need, which determines the 'logic of selection'. The theory of action thereby forms the nomological core of any sociological explanation. It is the causal connection between individual properties on the one hand, and the choice of a particular alternative on the other hand. Without bridge hypotheses it would be impossible to understand the individual's action, because the framing conditions of the action theory were not defined. Thirdly, the 'logic of aggregation' needs to be clarified, i.e. the rules by which the consequences of individual actions are transformed into a collective social outcome. Only if all three steps are taken, it is possible to explain transitions from one social situation or collective state to another. 
Since (regional) fertility and marriage rates are the social outcome of individual family formation decisions, a simple aggregation mechanism suffices to account for the transformation problem (e.g., Münch and Smelser 1987: 376f.). As a rule for the selection of an action, we suggest a flexible homo socio-oeconomicus type of rational actor model (cf. Lindenberg 1990). The remaining parts of this section elaborate on the first step of explanation introduced above, i.e. the 'logic of the situation'. After a general discussion of how the actor's situation is structured, a set of bridge hypotheses about the empirical relationship between properties of regional social contexts in western Germany and women's entry into motherhood and first marriage in the 1980s and 1990s will be proposed.

\subsection{Determinants of the actor's situation}

The logic of a situation is structured by the external and internal conditions significant for the actor's behavior. While the latter may be described as individual background (see below), the external conditions can be defined as social context. With regard to the empirical subject of this study, the following discussion at some points explicitly refers to regional social contexts, but the underlying logic can be applied to other forms of social context as well.

When summarizing different approaches to the question of the relevance of macro-level phenomena for the actions and interactions of individuals and groups, Münch and Smelser (1987: 381f.) conclude that a "common solution [...] is to conceive of macrophenomena as limiting frames of reference that set the agenda for microprocesses." In this sense, regional social contexts can be conceptualized as consisting of basically three components: social reference frames (e.g. norms), cultural 
reference frames (e.g. values), and opportunity structures (e.g. infrastructure). Each of these components is characterized by specific collective properties, which translate into contextual properties of individuals (Lazarsfeld and Menzel 1969), i.e. into relatively invariant structural parameters of the actor's behavior. ${ }^{2}$ This constitutes that part of the interdependent relationship between social entities at different levels of a multilevel system in which we are interested in this study (see e.g., Erbring and Young [1979] for a discussion of endogenous feedbacks in the relation between individuals and social structure).

In correspondence with Durkheim's notion of 'social facts', two sets of structural parameters can be distinguished. The first one "consists of the aggregative or distributive outcomes of choices of alternatives", whereas the second set of macro-level parameters "is the institutional or collective set, which [...] consists of structural constraints on available alternatives." (Hernes 1976: 516) Due to the regulative or conditioning character of higher-order entities for such of lower order, the relations between individual and collective entities within a multilevel system are qualitatively asymmetric. Such a multilevel structure, however, is neither one-way, nor completely deterministic, since lower-order entities (individuals) react selectively to their context and have the ability to reflect their own behavior (Huinink 1989: Chapter 2.2).

While the relations between entities at the same level define the horizontal structure of a multilevel system, the relations between entities at different levels

\footnotetext{
${ }^{2}$ Empirically this means that by disaggregation all individuals receive the value of the aggregate variables for the context which they are part of. As a result, the data file that is to be analyzed contains both individual-level variables and higher-level (contextual) variables in the form of the disaggregated collective variables. Treating the data as if they were independent would exaggerate the actual sample size for the contextual variables, thus causing spuriously significant results (e.g., Snijders and Bosker 1999: Chapter 3.2).
} 
constitute its vertical structure (Huinink 1989: Chapter 2.4). One possible variant of the vertical structure are 'organizational hierarchies', where the superiority of higher-order entities is based on power. These can be distinguished from 'aggregate hierarchies', where the ability to set structural parameters for lower-order entities is based on the greater 'persistence' of higher-order entities and their attributes. The relative inertia at the aggregate level is suggested to be the result of time-scale differentials between the various system levels (Huinink 1989: Chapter 2.4.3.1): while individuals act with reference to a comparatively short-term time-scale, macro-level processes require a rather long-term time-scale, since they are the result of many actions and interactions at the micro level.

Using the same concept of asymmetric relations, it would also be possible to introduce an 'internal multilevel hierarchy', which would then refer to psychological processes particular to each individual. This issue will not be addressed here any further, but it leads into the discussion of the role that the actor's individual background plays in structuring the logic of the situation.

There are basically two dimensions that form the individual's background. First, every individual has (more or less) access to or control over various resources, such as economic, social, and cultural capital. In addition, one may consider her biological and psychic capital. The latter points to the second main component of the individual background, which is defined here as the actor's psycho-social disposition, or identity. This includes such elements as values, attitudes, expectations, and eventually her preference structure. In sum, the subjective perception of the situation and "the plans individuals seek to carry out are determined by their expectations about the future and about the distribution of possibilities, by their interests, and by the means they control. 
All of these are dependent on preceding outcomes and are revised or undergo change from time to time, mainly as a result of previous actions" (Hernes 1976: 515).

\section{3 'Bridges' from macro to micro: How regional social contexts operate on individual}

\section{family formation decisions}

The implementation of aggregate-level variables in empirical investigations of individual decision-making has often been questioned on quite general methodological grounds. Main arguments in this discussion are the assertion that observed contextual effects often result from an omission of relevant individual-level characteristics, and that many studies do not sufficiently lay out the social mechanisms responsible for the transfer between contextual properties and the actor's behavior (e.g., Hauser 1974).

Thus - in advance of our empirical analysis - we carefully need to consider what might be important 'controls' for the individual's background, and through which processes contextual effects operate. Jencks and Mayer (1990: 113), for example, distinguish among epidemic (or contagion) models, collective socialization (or social control) models, and institutional models of neighborhood effects. Hank (2001b) argues that regional opportunity structures as well as local patterns of social interaction and culture may translate into parameters that directly affect individual behavior. In the following a set of bridge hypotheses is proposed that briefly describes our key assumptions about possible empirical relationships in the analysis of regional social contexts in western Germany and women's family formation decisions in the 1980s and 1990s. Many variables suggested here have been shown in prior studies to influence women's fertility and marital behavior and will therefore not be discussed in detail. 


\section{Individual characteristics}

An individual's age clearly is the most important biosocial determinant of her position in the life-course. A non-monotonic effect is assumed, i.e. women's propensity to enter motherhood and marriage should first increase with age, but decrease at later stages of her life course.

The influence of an individual's human capital characteristics on the process of family formation has been analyzed extensively not only within the framework of the 'new home economics' (e.g., Becker 1993: Chapter 5), but also from the perspective of sociologists (e.g., Blossfeld and Huinink 1991) and demographers (e.g., Rindfuss, Morgan, and Offut 1996). Due to higher investments in human capital, more highly educated women (i) gain economic independence and face higher opportunity costs of childrearing than their less educated counterparts, but at the same time (ii) they are more attractive partners on the marriage market and have a greater economic potential to support a family. Thus the direction of the level-of-education-effect on the individual's propensity to form a family cannot be predicted unambiguously. In any case, a woman's risk of entering marriage and/or parenthood should be lowest, as long as she is enrolled in education.

Finally, being married (being a mother, respectively) as well as having a foreign background $^{3}$ is supposed to increase a woman's probability to enter motherhood (marriage, respectively).

\footnotetext{
${ }^{3}$ In western Germany, so called 'guest workers' - mainly from southern Europe and Turkey and their descendants account for the largest share of the foreign population. These citizens are likely to have more traditional values than their native German counterparts.
} 


\section{Regional characteristics}

One of the main determinants of the living conditions in an individual's environment are local opportunity structures. These should be reflected in part by the degree of urbanization. Since urban areas generally offer more alternatives to traditional family formation and provide a less appropriate environment for rearing children than rural areas, it is assumed that women exhibit a decreasing propensity to marry and have a child, if the population density of their residential district increases (e.g., Huinink and Wagner 1989; Lichter, LeClere, and McLaughlin 1991).

The availability of children's day care plays a crucial role for the compatibility of childrearing and female employment and therefore becomes a central element of a region's opportunity structure. Since the availability of adequate childcare reduces the opportunity costs of childrearing for women who want to participate in the labor force, a woman should be more likely to have children if the public provision of day care increases (e.g., Kravdal 1996).

A shortage in the number of desirable partners on the marriage market, e.g. due to an imbalanced sex ratio, should lead to relatively high proportions unmarried or to a delay of marriage. Hence, it is generally predicted that women encountering numerous men in the local marriage market will have high marriage rates (e.g., South and Lloyd 1992).

The availability of jobs in the tertiary sector is considered to favor women's career prospects (e.g., Blossfeld 1987), which should increase women's economic independence and the opportunity costs of motherhood. Thus it is assumed that a woman's probability of getting married and having a child decreases, if the share of jobs in the service sector increases. 
The direction of an effect of the regional unemployment rate on fertility is difficult to predict (e.g., De Cooman, Ermisch, and Joshi 1987). Since the labor supply of women partly depends on the demand for labor, a woman's probability to have a child is supposed to move in step with the unemployment rate, because (at least in the short run) this would minimize the actual opportunity costs of reducing or giving up market work for starting a family. On the other hand, the local labor market situation is an indicator of a community's socio-economic status and the economic situation in general. Thus women are expected to be more likely to have a child if unemployment decreases, since children might be considered as being more affordable, if economic prospects are evaluated positively (e.g., Hoem 2000: Section 5).

The regional unemployment rate may also have an ambiguous influence on women's entry into marriage. If the labor market situation is perceived as difficult, women could seek economic security in a marriage, where they pool their income with the partner's earnings. However, high unemployment also reduces the number of economically attractive partners on the marriage market, which might result in delayed marriage (e.g., Lichter et al. 1991).

The total effect of the aggregate female labor force participation on family formation is unclear, too (see Brewster and Rindfuss [2000] for a recent review). Female employment rates clearly mark the degree to which women are expected and able to constitute economic independence from a husband's support. Since women's motivation to work in the market (and delay or even forgo traditional family formation) is supposed to be positively influenced by the role model of other women, a woman's propensity for having a child and contracting a marriage is expected to decrease with an increasing female labor force participation rate. However, a high labor force 
participation of women could also induce favorable changes in the interplay between the family and labor market institutions, which might eventually account for the needs of working mothers. Thus a woman's probability to have a child possibly increases with a growing participation of women in the labor market.

Finally, actors are likely to be influenced by behavioral expectations and actual behavior they witness in their social environment. South and Crowder (2000: 1069), for example, point out that socially dislocated areas may "lack successful marital role models that signal the benefits of marriage and provide the normative expectations to marry." Moreover, there is accumulating evidence suggesting the existence of age- and sequencing-norms related to a variety of family transitions (e.g., Blossfeld and Huinink 1991, Settersten and Hägestad 1996). Since 'conservative' cultural forces are assumed to have a stronger effect in homogeneous social contexts, a woman's propensity to form a family is supposed to be higher in areas characterized by high birth rates (marriage rates, respectively) and a single predominant ideational orientation, which may be expressed by denominational affiliation or by support for a political party (e.g., Lesthaeghe and Surkyn 1988).

\section{Data and methods}

\subsection{Data, variables, and description of the sample}

The individual-level data used in this paper were made available by the German SocioEconomic Panel Study (GSOEP) at the German Institute for Economic Research (DIW Berlin) (see SOEP Group [2001] for a description of the data set). This longitudinal micro-database provides socio-economic information on currently more than 7,000 
households (including an oversample of foreign-headed households) and 14,000 individuals in eastern and western Germany. The survey was started in the western states of Germany and is conducted annually since 1984. The full birth biography and marital history of all women who participate in the survey is provided with the data. Only the transition to the first child and the first marriage will be considered here.

The GSOEP can be linked to Kreise, i.e. district-level data. ${ }^{4}$ The population size of Kreise ranges from roughly 50,000 to around 700,000, averaging at about 200,000 (cities of one million or more inhabitants excluded). Among the 328 western German Kreise (including West-Berlin), it is possible to distinguish between urban kreisfreie Städte and rural Landkreise. The latter cover on average about 30 municipalities, while kreisfreie Städte usually consist of a single urban municipality only.

The observation period covers the years 1984 to 1999 , i.e. all currently available waves of the GSOEP. However, information on the regional variables of interest is mostly available for two points in time only. The 'DJI Regionaldatenbank' provides regional indicators at the Kreis level for the second half of the 1980s. ${ }^{5}$ In addition, regional information for the mid-1990s is drawn from the 'Statistik regional' database (Statistische Ämter des Bundes und der Länder 1999). The observation period is therefore divided into two halves, from 1984 to 1991, and from 1992 to 1999, respectively. Time-varying variables are assumed to be time-constant within each of the two periods, and are allowed to vary only between the two periods defined above.

Table 1 provides an overview of the individual-level and contextual variables that will be used in the empirical analysis.

\footnotetext{
${ }^{4}$ Due to German data protection regulations, the combined data set may be analyzed exclusively at the DIW Berlin.

${ }^{5}$ See $h t t p: / / w w w . d j i . d e / 2 \_r d b / d e f a u l t . h t m$ for more information.
} 
[Table 1 about here]

Only respondents from the two original GSOEP subsamples are included in the analysis, i.e. western Germans and foreigners from Greece, Italy, Spain, Turkey, and former Yugoslavia, who already lived in Germany in 1984. Individuals who migrate during the study period from one Kreis to another are followed to their new place of residence. The sample for the analysis of first births consists of 2,892 women, who are observed from age 20 onwards, unless this age was reached before the first year of observation. The upper age limit is 35 years. Since each individual is allowed to contribute multiple observations, this leads to 13,537 individual records, nested within 300 Kreise (out of 328 Kreise in the population). The number of observed first births in the period 1984 to 1999 is 1,025 . The sample for the analysis of first marriages is restricted to 2,266 never-married women aged 20 to 35 who live in 288 Kreise. This results in 10,077 individual records and 746 events. See Table 2 for further descriptive sample statistics.

[Table 2 about here]

\subsection{Methods}

This study uses discrete-time multilevel models to estimate a woman's risk of entering motherhood (first marriage, respectively) within a one-year interval in the observation period (see Barber et al. [2000] for a thorough methodological discussion). A common choice to specify how the discrete-time hazard rate is determined, is the logistic regression function. The logit model provides a good approximation to the continuous 
time proportional hazards model, if the conditional probabilities that an event occurs at time $t$, given that it has not already occurred, are sufficiently small (Yamaguchi 1991).

The discrete-time logit model estimates the effect of a number of covariates on the $\log$ of the odds of an event. However, if individuals are clustered within the same context, the standard assumption of independent disturbances is violated. This may result in inefficient estimates of the macro-level parameters and downwardly biased estimates of their standard errors. Hierarchical generalized linear models - as an extension of random coefficient models - can be used to overcome these problems. They allow the application of multilevel logistic regression models for the analysis of discrete dependent variables (see Guo and Zhao [2000] for an overview). In these models, coefficients may be fixed or random, where the choice between the two alternatives can be made separately for each coefficient in the equation. In the analysis performed here, all regression coefficients other than the intercept are constrained to be fixed across the regional units, i.e. we assume that the effect of the explanatory variables does not differ between contexts ('random intercept model'; see Snijders and Bosker [1999: Chapter 4]).

In the present case, the log odds that a woman experiences a first birth (first marriage, respectively) within the one-year interval $t$ is

$$
\log \left[p_{i j t} /\left(1-p_{i j t}\right)\right]=b_{0}+b_{1} x_{i j}+b_{2} z_{i j t}+b_{3} v_{j}+b_{4} w_{j t}+u_{0 j}
$$

where $p_{i j t}$ is the probability of individual $i$ in region $j$ to experience a birth (marriage, respectively) in year $t, x_{i j}$ and $v_{j}$ are vectors of individual- and macro-level time-constant explanatory variables, and $z_{i j t}$ and $w_{j t}$ are vectors of time-varying explanatory variables at time $t$. The random intercept's fixed component $b_{0}-$ which is constrained to be equal across all years - and the slopes $b_{1}$ to $b_{4}$ are the parameters of the equation. The macro- 
level error term $u_{0 j}$ is the regional-level random effect, where the same $u_{0 j}$ applies to all observations in a particular region. It indicates that the intercept may vary over contexts, i.e. $u_{0 j}$ measures the deviation of each context from $b_{0}$ ('between-context variance'). This captures otherwise unobserved regional effects and accounts for the correlation between individuals nested within the same context. The macro-level disturbances $u_{0 j}$ are assumed to be normally distributed, with the expected value 0 and the variance $\sigma_{u}^{2}$. If the $u_{0 j}$ turn out to be statistically significant from zero, context effects are present. Since entry into motherhood and first marriage are non-repeatable events, no individuallevel unobserved heterogeneity factors can be identified.

Discrete-time logit models use multiple observations for each individual in the sample, i.e. each time unit during which an individual is observed contributes a separate observation to the input data. For each of these observations, the dependent variable is coded 1 if the event occurs, 0 otherwise.

\section{Regression results}

The results of the multivariate analysis are presented separately for first births and first marriages. Since our main interest is on contextual effects, the findings for the individual-level coefficients are only briefly reported. The final models are build-up in several steps, starting from an 'empty model' with just the intercept and the regional random effect (Model 1). The individual-level control variables are introduced in Models 2 to 4, and the district-level contextual variables are eventually added in Models 5 to 7 . The regression results for the analysis of women's entry into motherhood are displayed in Table 3 , while the results for women's entry into first marriage are shown 
in Table 4. The analysis is performed using the software package $a M L$ (see Lillard and Panis [2000]).

\section{Entry into motherhood}

The coefficients of the individual-level control variables come out as expected. In addition to a non-monotonic age effect (Model 2), being in education strongly reduces the propensity to have a first child (Model 3), and the risk of married western German women to experience a first birth is many times higher than for their unmarried counterparts (Model 4). Including a woman's marital status in the analysis results in a substantial improvement in the model's fit and clearly reduces the initial size of the other individual-level coefficients.

Turning to the contextual variables, we find a highly significant regional random effect $\left(\sigma_{u}\right)$ on women's risk of entering motherhood in the 'empty' Model 1. This indicates that the intercept varies over Kreise, and it can be seen from Models 2 and 3 that the contextual effect remains after age and education are controlled for. However, once the marital status is entered into the regression, $\sigma_{u}$ virtually disappears (Model 4). Adding the 'rural-urban' variables nevertheless leads to a weakly significant improvement of the fit in Model 5. The coefficient of the dummy variable indicating residence in a rural Kreis is statistically significant, and the direction of the effect is consistent with our hypothesis that women in less urbanized areas have a higher propensity for having a child. However, this effect becomes weaker and insignificant in Models 6 and 7, where additional regional variables are included in the analysis. None of these has any measurable impact on a woman's first birth risk, though. 
In line with results reported in Hank (2001b), where 75 Raumordnungsregionen were used as regional context, our findings suggest that basically all regional heterogeneity in women's transition to parenthood should be due to differences in the population composition, independent of the definition of context. ${ }^{6}$ The extraordinarily strong impact of the respondent's marital status is consistent with other research indicating a clear tendency towards 'child oriented' marriages in western Germany (e.g., Konietzka and Kreyenfeld 2001). If Model 7, for example, is run without controlling for marital status (not shown here), it turns out that the size of $\sigma_{u}$ remains in the same order of magnitude as in the models without any direct regional-level indicators. The (insignificant) outcome of the other contextual variables, though, is barely affected by an omission of the marriage variable.

[Table 3 about here]

\section{Entry into first marriage}

The direction of the effects of the individual-level control variables on the probability to enter first marriage is generally the same as in the 'fertility analysis' and thus consistent with our theoretical expectations. The strength of the effects of age and enrollment in education turns out to be somewhat larger, though. Terminating education without degree is found to reduce a woman's marriage risk. The size of the respective coefficient increases and becomes statistically significant after it is controlled for the presence of a child (Model 4). This indicates that the lower marriage propensity of women without degree is underestimated, if one does not account for their higher risk of

\footnotetext{
${ }^{6}$ When analyzing the transition to the second child, Hank (2001b) finds that the initially significant regional random effect disappears, as soon as age-related variables (including the woman's age at first birth) are controlled for in the model.
} 
unmarried childbearing, which subsequently leads to a higher probability to marry among mothers with no degree. ${ }^{7}$ The strong and positive impact of the 'child' dummy is as expected. Inclusion of this variable improves the model fit substantially, but does not reduce the effect of the other individual-level variables. Finally, being a foreigner increases a woman's probability to contract a marriage, although the coefficient is significant at the 10 per cent level only.

With regard to contextual influences, there is no statistically significant effect of any of the district-level variables introduced in Models 5 to 7. A temporary increase of the 'rural' coefficient disappears after adding the ideational homogeneity index to the regression. The coefficient of the latter turns out to be weakly significant, however, with an unexpected negative sign. This points to the presence of unobserved confounding socio-cultural factors, which are captured by $\sigma_{u}$. The initial value of the regional random effect is not reduced by any of the individual-level or contextual variables and remains highly significant throughout all models.

[Table 4 about here]

\section{Discussion}

While contextual effects on an actor's behavior are difficult to tackle empirically, consideration of her social context is nevertheless an indispensable step in any model of sociological explanation. Thus we suggest a multilevel model of regional social contexts and individual family formation behavior, where particular attention is paid to the determinants of the actor's situation, i.e. the 'logic of the situation'. A set of bridge

\footnotetext{
${ }^{7}$ An interaction between having no degree and having a child (not shown here) supports this view.
} 
hypotheses about the empirical relationship between properties of western German Kreise and women's decisions concerning the entry into motherhood and first marriage in the 1980s and 1990s is then proposed and subsequently tested in a multivariate analysis.

In the first part of the empirical analysis, none of the estimated multilevel discrete-time logit models provides evidence for a persistent autonomous influence of characteristics of a woman's residential district on her first birth risk. Consistent with findings from a recent study that operationalizes the social context at a higher level of spatial aggregation (Hank 2001b), basically all regional heterogeneity in women's transition to parenthood appears to be due to differences in the population composition, particularly regarding the respondents' marital status. From this, one might derive the hypothesis that contextual influences on the entry into motherhood - for which we have argued above - are mediated through contextual influences on union formation behavior.

The second part of the empirical analysis, dealing with women's entry into first marriage, reveals no measurable 'structural' contextual effects (e.g. related to the local marriage or labor market) either. However, we find a constant and significant variation of the regression intercept across Kreise, which suggests that unobserved regional nuptiality customs (e.g. regarding the timing of marriage) might exhibit a considerable influence on women's marriage decisions until today.

Such customs, for which our measure of the crude marriage rate is apparently unable to account, are likely to be embedded in broader and probably longstanding socio-cultural contexts. An examination of the age at marriage and control of marital fertility in a variety of geographical settings indicates that at least in pre-transitional 
societies "the social context in which late marriage is the norm is one in which women have more autonomy and are freer to adopt control over their childbearing." (Coale 1992: 340) Although the historical structural circumstances that originally fostered later marriage in some areas (e.g. specific inheritance rules) may have changed, local subcultures that evolved in the demographic and ideational domain often turn out to be extremely stable across time (Lesthaeghe and Neels 2001). However, the persistence of spatial differentials in life-course patterns should depend increasingly on variations in the spread of broader value orientations (e.g., Lesthaeghe and Moors 2000) and "internalized norms about age-appropriate behavior, age-graded events and transitions, and age-sequential rules [...] as societal regulation became more lenient." (Heckhausen 1999: 35 ; italics not in the original $)^{8}$

For the western German society, it is plausible to assume a 'sequencing norm' prescribing completion of education before marriage (Blossfeld and Huinink [1991]; also see Rindfuss et al. [1996: 279]), and marriage before parenthood (Billari and Kohler forthcoming; Konietzka and Kreyenfeld 2001). Although longer enrollment in education leads to a general postponement of family formation, controlling for women's education in our analysis could not explain regional variations in their probability of entering first marriage. Neither were differentials in women's experience of premarital childbearing able to account for the observed district-level differences in marriage risks, while, on the other hand, women's marital behavior absorbed virtually all regional heterogeneity in their propensity to have a first child during the observation period. Thus, regional nuptiality customs, which might also mark spatial differentials in the

\footnotetext{
${ }^{8}$ It is important to note that the idea of 'internalized norms' rather refers to flexible guidelines for family transitions than to inflexible normative principles (cf. Settersten and Hägestad 1996).
} 
balance between individual autonomy and traditional forms of authority, must probably be understood as the principal origin of different patterns of fertility across western German Kreise.

Unfortunately, our analysis could reveal only indirect evidence for the existence of regional nuptiality customs and their subsequent influence on women's first birth risks. Direct investigation of regional variations in such customs and related norms requires of course richer data than those that are usually available from social science surveys. Researchers should therefore make an effort to collect more qualitative data, possibly through ethnographic observation that allows for comparative studies of the relevant spatial and social units. 


\section{References}

Alexander, J.C., B. Giesen, R. Münch, and N.J. Smelser (eds.). 1987. The MicroMacro Link. Berkley: University of California Press.

Barber, J.S., S.A. Murphy, W.G. Axinn, and J. Marples. 2000. "Discrete-time multilevel hazard analysis." Pp.201-235 in Sociological Methodology, vol. 30, edited by M.E. Sobel and M.P. Becker. Washington: Blackwell Publishers.

Bauereiß, R., H. Bayer, and W. Bien. 1997. Familienatlas II: Lebenslagen und Regionen in Deutschland. Opladen: Leske+Budrich.

Becker, G.S. 1993. A Treatise on the Family (Enlarged Edition). Cambridge: Harvard University Press.

Billari, F.C., H.-P. Kohler. Forthcoming. "The impact of union formation dynamics on first births in West Germany and Italy: Are there signs of convergence?” Pp.xx-xx in Comparative Research on Fertility and the Family in Contemporary Europe: Findings and Lessons, edited by E. Klijzing and M. Corijn. New York and Geneva: United Nations.

Billy, J.O., K.L. Brewster, and W.R. Grady. 1994. "Contextual Effects on the Sexual Behavior of Adolescent Women." Journal of Marriage and the Family 56: 387404.

and D.E. Moore. 1992. “A multilevel analysis of marital and nonmarital fertility in the U.S." Social Forces 70: 977-1011.

Blossfeld, H.-P. 1987. "Labor-Market Entry and the Sexual Segregation of Careers in the Federal Republic of Germany.” American Journal of Sociology 93: 89-118. and J. Huinink. 1991. "Human Capital Investments or Norms of Role Transition? How Women's Schooling and Career Affect the Process of Family Formation." American Journal of Sociology 97: 143-168. 
Brewster, K.L. and R.R. Rindfuss. 2000. "Fertility and Women's Employment in Industrialized Nations.” Annual Review of Sociology 26: 271-296.

Burton, L.M. and R.L. Jarrett. 2000. "In the Mix, Yet on the Margins: The Place of Families in Urban Neighborhood and Child Development Research.” Journal of Marriage and the Family 62: 1114-1135.

Coale, A.J. 1992. "Age of Entry into Marriage and the Date of the Initiation of Voluntary Birth Control.” Demography 29: 333-341.

Coleman, J.S. 1990. Foundations of Social Theory. Cambridge: Harvard University Press.

De Cooman, E., J. Ermisch, and H. Joshi. 1987. "The next birth and the labour market. A dynamic model of births in England and Wales." Population Studies 41: 237268.

DiPrete, T.A. and J.D. Forristal. 1994. "Multilevel Models - Methods and Substance." Annual Review of Sociology 20: 331-357.

Erbring, L. and A.A. Young. 1979. "Individuals and Social Structure. Contextual Effects as Endogenous Feedback.” Sociological Methods \& Research 7: 396-430.

Esser, H. 1996. Soziologie. Allgemeine Grundlagen (Second Edition). Frankfurt a. M. and New York: Campus.

------ . 1998. “Why are Bridge Hypotheses Necessary?” Pp.94-111 in Rational Choice Theory and Large-Scale Data Analysis, edited by H.-P. Blossfeld and G. Prein. Boulder: Westview Press.

Ginther, D., R. Haveman, and B. Wolfe. 2000. "Neighborhood Attributes as Determinants of Children's Outcomes." The Journal of Human Resources 35: 603-642.

Guo, G. and H. Zhao. 2000. "Multilevel Modeling for Binary Data." Annual Review of Sociology 26: 441-462. 
Hank, K. 2001a. "Regional Fertility Differences in Western Germany: An Overview of the Literature and Recent Descriptive Findings." International Journal of Population Geography 7: 243-257.

. 2001b. "Regional Social Contexts and Individual Fertility Decisions: A Multilevel Analysis of First and Second Births in Western Germany." MPIDR Working Paper WP 2001-015, available http://www.demogr.mpg.de/Papers/Working/wp-2001-015.pdf.

Hauser, R.M. 1974. "Contextual Analysis Revisited." Sociological Methods \& Research 2: 365-375.

Heckhausen, J. 1999. Developmental Regulation in Adulthood. Age-Normative and Sociostructural Constraints as Adaptive Challenges. Cambridge: Cambridge University Press.

Hernes, G. 1976. "Structural Change in Social Processes." American Journal of Sociology 82: 513-547.

Hoem, B. 2000. "Entry into motherhood in Sweden: the influence of economic factors on the rise and fall in fertility, 1986-1997." Demographic Research [Online] 2, available http://www.demographic-research.org/Volumes/Vol2/4.

Huber, J. (ed.). 1991. Macro-Micro Linkages in Sociology. Newbury Park: Sage.

Huinink, J. 1989. Mehrebenensystem-Modelle in den Sozialwissenschaften. Wiesbaden: Deutscher Universitäts-Verlag.

----- and M. Wagner. 1989. "Regionale Lebensbedingungen, Migration und Familienbildung." Kölner Zeitschrift für Soziologie und Sozialpsychologie 41: 669-689.

Jencks, C. and S.E. Mayer. 1990. "The Social Consequences of Growing Up in a Poor Neighborhood." Pp.111-186 in Inner-City Poverty in the United States, edited by L.E. Lynn and M.G.H. McGeary. Washington: National Academy Press. 
Konietzka, D. and M. Kreyenfeld. 2001. "Non-Marital Births in East Germany after Unification." MPIDR Working Paper WP 2001-027, available http://www.demogr.mpg.de/Papers/Working/wp-2001-027.pdf.

Kopp, J. 2000. "Geburtenentwicklung in Ost- und Westdeutschland." Pp.83-135 in Solidarität, Lebensformen und regionale Entwicklung, edited by H. Bertram et al. Opladen: Leske+Budrich.

Kravdal, Ø. 1996. "How the local supply of day-care centers influences fertility in Norway: A parity-specific approach." Population Research and Policy Review 15: 201-218.

Lazarsfeld, P.F. and H. Menzel. 1969. "On the relations between individual and collective properties." Pp.499-516 in A sociological reader on complex organizations, edited by A. Etzioni. New York: Holt, Rinehart \& Winston.

Lestaheghe, R. and G. Moors. 2000. "Life course transitions and value orientations: selection and adaptation." Interuniversity Papers in Demography WP 2000-7, available http://www.vub.ac.be/SOCO/IPDWP2000-7.pdf.

Lesthaeghe, R. and K. Neels. 2001. "From the First to the Second Demographic Transition: an Interpretation of the Spatial Continuity of Demographic Innovation in France, Belgium and Switzerland." Paper prepared for the Euresco Conference on 'The Second Demographic transition in Europe', Bad Herrenalb, June 23-28.

Lesthaeghe, R. and J. Surkyn. 1988. "Cultural Dynamics and Economic Theories of Fertility Change." Population and Development Review 14: 1-45.

Lichter, D.T., F.B. LeClere, and D.K. McLaughlin. 1991. "Local Marriage Markets and the Marital Behavior of Black and White Women." American Journal of Sociology 96: 843-867.

Lillard, L.A. and C.W.A. Panis. 2000. aML Multilevel Multiprocess Statistical Software, Release 1.0. Los Angeles: EconWare. 
Lindenberg, S. 1990. "Homo Socio-Oeconomicus: The Emergence of a General Model of Man in the Social Sciences." Journal of Institutional and Theoretical Economics 146: 727-748.

Münch, R. and N.J. Smelser. 1987. "Relating the Micro and Macro." Pp.356-388 in The Micro-Macro Link, edited by J.C. Alexander et al. Berkley: University of California Press.

Rindfuss, R.R., S.P. Morgan, and K. Offutt. 1996. "Education and the Changing Pattern of American Fertility: 1963-1989.” Demography 33: 277-290.

Settersten, R.A. and G.O. Hägestad. 1996. "What's the Latest? Cultural Age Deadlines for Family Transitions." The Gerontologist 36: 178-188.

Snijders, T.A.B. and R.J. Bosker. 1999. Multilevel analysis: An introduction to basic and advanced multilevel modeling. London: Sage.

SOEP Group. 2001. "The German Socio-Economic Panel (GSOEP) after more than 15 years - Overview." Pp.7-14 in Proceedings of the 2000 Fourth International Conference of German Socio-Economic Panel Study Users (GSOEP2000) (Vierteljahrshefte zur Wirtschaftsforschung 70), edited by E. Holst et al.

South, S.J. 2001. "The Geographic Context of Divorce: Do Neighborhoods Matter?" Journal of Marriage and the Family 63: 755-766.

and K.D. Crowder. 2000. "The declining significance of neighborhoods? Marital transitions in community context." Social Forces 78: 1067-1099.

------ and K.M. Lloyd. 1992. "Marriage Markets and Nonmarital Fertility in the United States." Demography 29: 247-264.

Statistische Ämter des Bundes und der Länder (eds.). 1999. Statistik regional - Daten und Informationen der statistischen Ämter des Bundes und der Länder. CD-ROM.

Yamaguchi, K. 1991. Event History Analysis. Newbury Park: Sage. 


\section{Tables}

Table 1: Variable description

\begin{tabular}{|c|c|}
\hline \multicolumn{2}{|r|}{ Dependent variables } \\
\hline First birth / First marriage & $\begin{array}{l}\text { Binary variable that equals } 1 \text {, if the woman experiences her first birth } \\
\text { (marriage, respectively) within a one-year interval in the period } 1984 \\
\text { to } 1999 .\end{array}$ \\
\hline \multicolumn{2}{|r|}{ Individual characteristics } \\
\hline Age & Woman's age and age-squared. The age range is 20 to 35 years. \\
\hline Education & $\begin{array}{l}\text { Time-varying binary variables, indicating the woman's highest } \\
\text { educational degree at the time of the interview: in education, no } \\
\text { degree, vocational degree (reference category), university degree. }\end{array}$ \\
\hline Marital status $^{\mathrm{a}}$ & Time-varying binary variable that equals 1 , if the woman is married. \\
\hline Child $^{\mathrm{b}}$ & $\begin{array}{l}\text { Time-varying binary variable that equals } 1 \text {, if the woman is mother of } \\
\text { (at least) one child. }\end{array}$ \\
\hline Foreigner & $\begin{array}{l}\text { Time-constant binary variable that equals } 1 \text {, if the woman belongs to } \\
\text { the foreigner-sample of the GSOEP. }\end{array}$ \\
\hline \multicolumn{2}{|r|}{ Regional characteristics } \\
\hline Degree of urbanization & $\begin{array}{l}\text { Time-constant binary variables, indicating whether the district is } \\
\text { defined as agglomeration (reference category), as urban area, or as } \\
\text { rural area. }\end{array}$ \\
\hline Day-care provision $^{\mathrm{a}}$ & $\begin{array}{l}\text { Local provision of day care slots in Kindergarten per } 1000 \text { children } \\
\text { aged 3-6 (time-varying, 1986/1994). }\end{array}$ \\
\hline Proportion of men ${ }^{b}$ & $\begin{array}{l}\text { Average proportion of men in the local population aged } 25 \text { to } 30 \text { in } \\
1995-1997 \text { (in \%) (time-constant). }\end{array}$ \\
\hline Tertiary sector & Local share of employees in trade (in \%) (time-varying, 1987/1995). \\
\hline Unemployment rate & Local unemployment rate (in \%) (time-varying, 1987/1996). \\
\hline $\begin{array}{l}\text { Female labor force participation } \\
\text { rate (FLPR) }\end{array}$ & $\begin{array}{l}\text { Local female labor force participation rate (in \%) (time-varying, } \\
\text { 1987/1995). }\end{array}$ \\
\hline Crude birth rate $(\mathrm{CBR})^{\mathrm{a}}$ & Average of local crude birth rates in 1989 and 1995 (time-constant). \\
\hline Crude marriage rate $(\mathrm{CMR})^{\mathrm{b}}$ & $\begin{array}{l}\text { Average of local crude marriage rates in } 1986 \text { and } 1993 \text { (time- } \\
\text { constant). }\end{array}$ \\
\hline $\begin{array}{l}\text { Ideational homogeneity index } \\
\text { (IHI) }\end{array}$ & $\begin{array}{l}\text { Time-constant binary variable that equals } 1 \text {, if a single party received } \\
\text { more than } 50 \text { per cent of the local votes in two recent elections } \\
\text { (European parliament 1989, state parliament 1995/99), and more than } \\
\text { two thirds of the population share the same denominational affiliation } \\
\text { (Protestant or Catholic). }\end{array}$ \\
\hline \multicolumn{2}{|c|}{$\begin{array}{l}\text { Note: } \\
{ }^{a} \text { Variable is used in the analysis of first births only. } \\
\text { b Variable is used in the analysis of first marriages only. }\end{array}$} \\
\hline
\end{tabular}


Table 2: Descriptive sample statistics

\begin{tabular}{|c|c|c|}
\hline Variable & $\begin{array}{c}\text { First birth } \\
\text { Mean }(S t d v .)^{\mathrm{a}}\end{array}$ & $\begin{array}{l}\text { First marriage } \\
\text { Mean }(S t d v .)^{\mathrm{a}}\end{array}$ \\
\hline Individual level & & \\
\hline Age & $25.5(4.1)$ & $24.8(3.9)$ \\
\hline Age squared & $665.0(218.1)$ & $629.9(206.8)$ \\
\hline In education & .17 & .22 \\
\hline No degree & .18 & .17 \\
\hline Vocational degree & .57 & .53 \\
\hline University degree & .08 & .07 \\
\hline Marital status & .27 & - \\
\hline Child & - & .09 \\
\hline Foreigner & .23 & .22 \\
\hline Regional level & & \\
\hline Agglomeration & .60 & .59 \\
\hline Urbanized area & .25 & .25 \\
\hline Rural area & .15 & .15 \\
\hline Day-care provision & $825.5(175.0)$ & - \\
\hline Proportion of men & - & $51.3(1.2)$ \\
\hline Tertiary sector & $17.2(3.9)$ & $17.2(3.9)$ \\
\hline Unemployment rate & $8.7(3.2)$ & $8.8(3.2)$ \\
\hline FLPR & $41.2(3.5)$ & $41.4(3.5)$ \\
\hline CBR & $10.2(.9)$ & - \\
\hline CMR & - & $7.5(0.5)$ \\
\hline IHI & .10 & .10 \\
\hline $\mathrm{N}$ (events) & 1,025 & 746 \\
\hline $\mathrm{N}$ (districts) & 300 & 288 \\
\hline $\mathrm{N}$ (women) & 2,892 & 2,266 \\
\hline $\mathrm{N}$ (records) & 13,537 & 10,077 \\
\hline
\end{tabular}

Source: GSOEP 1984-1999, DJI Regionaldatenbank, Statistik regional 1999, author's calculations 


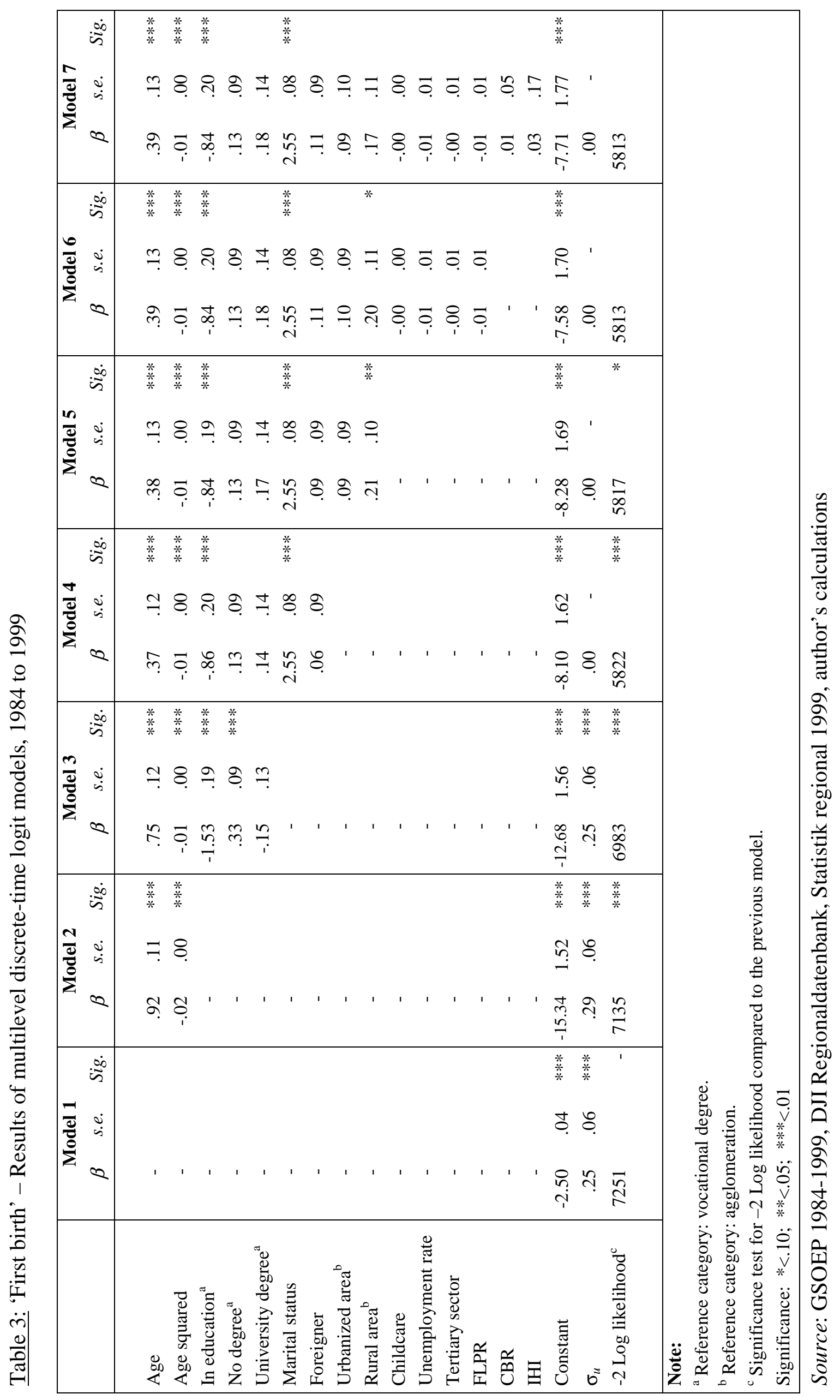




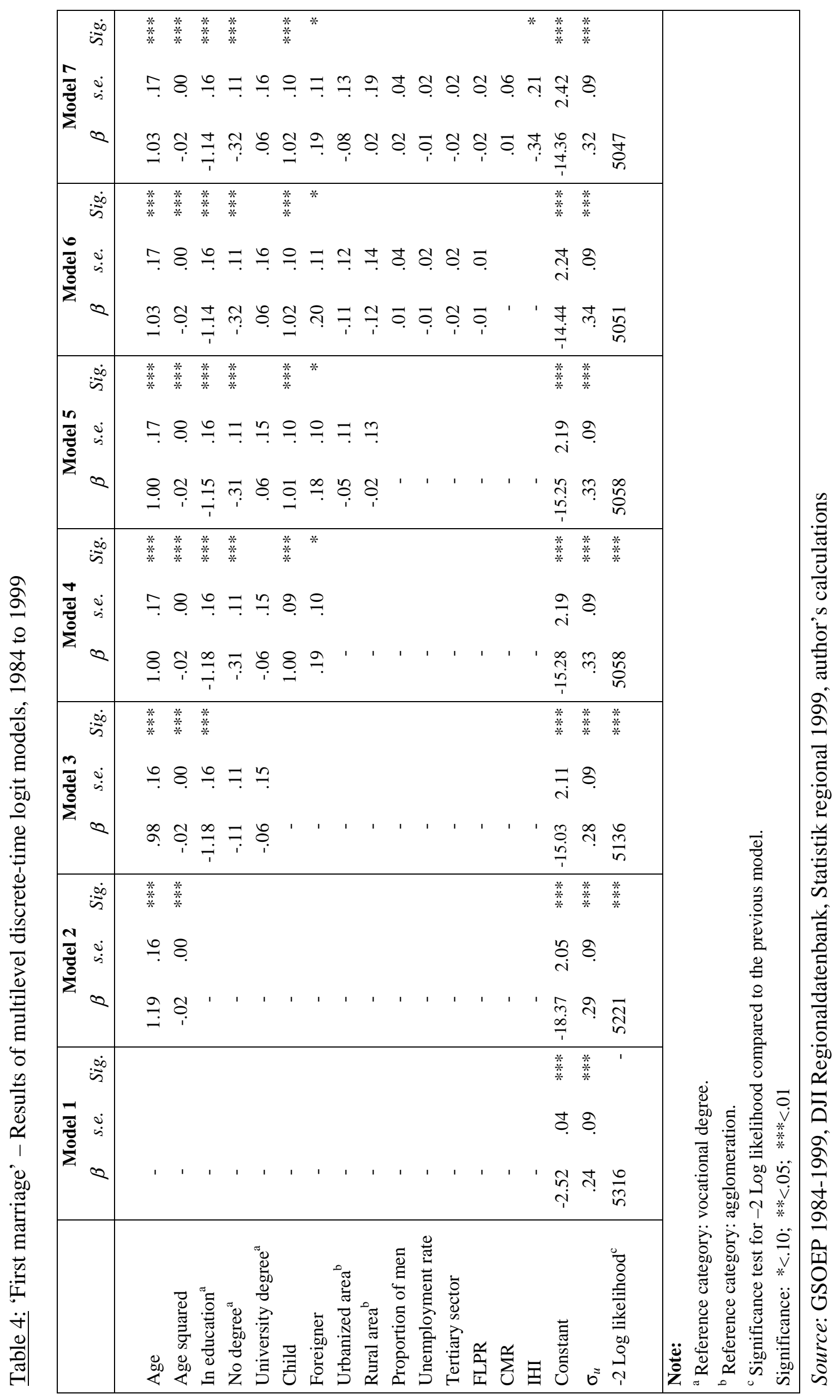

